JURNAL SOSIAL-EKONOMI PERTANIAN DAN AGRIBISNIS

JOURNAL ON SOCIO-ECONOMICS OF AGRICULTURE AND AGRIBUSINESS

e-ISSN: 2615-6628

Vol.13 No.1 28 Februari 2019

p-ISSN: $1411-7176$

\title{
ANALISIS RANTAI PASOKAN SAYURAN DI PASAR INDUK KOTA PANGKALPINANG
}

\author{
Yuni Kartika, Yudi Sapta Pranoto dan Fournita Agustina \\ Program Studi Agribisnis, Universitas Bangka Belitung \\ E-mail: 1696.yunikartika@gmail.com
}

HP: 085267143455

\begin{abstract}
ABSTRAK
Pasar merupakan tempat pertemuan antara pedagang dan pembeli sehingga proses pendistribusian produk dan jasa sering dilakukan di pasar baik pasar tradisional maupun pasar modern.Pendistribusian produk biasanya dilakukan secara langsung oleh distributor dengan pedagang sayuran sehingga terdapat perbedaan harga dan voume pada produk yang di jual oleh pedagang sayuran tersebut.Penelitian ini bertujuan untukmenghitung besar volume sayuran berdasarkan jenisnya yang masuk serta menganalisis faktor-faktor yang mempengaruhi tingkat volume sayuran yang masuk ke Pasar Induk Kota Pangkalpinang. Waktu dan tempat penelitian ini dilaksanakan pada bulan Desember 2017 sampai dengan bulan Januari 2019 di Pasar Induk Kota Pangkalpinang. Metode penelitian yang digunakan adalah metode studi kasus. Metode penarikan contoh yang digunakan adalah metode sensus dengan jumlah sampel 48 orang, yang terdiri dari 6 orang pedagang besar, 2 orang agen sayuran dan 40 orang pedagang pengecer. Metode analisis data yang digunakan adalah deskriptif kualitatif dan analisis regresi linier berganda. Hasil Penelitian menunjukkanVolume pasokan sayuran di Pasar Induk Kota Pangkalpinang berdasarkan jenisnya yaitu; jenis sayuran daun 114.750 kilogram per bulan, jenis sayuran buah 137.400 kilogram per bulan, jenis sayuran bunga 450 kilogram per bulan, jenis sayuran biji dan polong 17.400 kilogram per bulan dan jenis sayuran umbi 111.200 kilogram per bulan dan faktor-faktor yang mempengaruhi tingkat volume pasokan sayuran diantara 7 variabel penduga hanya 6 variabel yang berpengaruh secara statistik pada taraf 5 persen, dimana sig $<0,05$ yaitu harga $\left(X_{1}\right)$, keuntungan pedagang $\left(\mathrm{X}_{2}\right)$, transportasi $\left(\mathrm{X}_{4}\right)$, ketersediaan sayuran $\left(\mathrm{D}_{1}\right)$, kualitas sayuran $\left(\mathrm{D}_{2}\right)$ dan daerah pemasok $\left(\mathrm{D}_{3}\right)$.
\end{abstract}

Kata Kunci: pasar, rantai pasokan, sayuran dan volume pasokan

ANALYSIS OF VEGETABLE SUPPLY CHAINS IN PASAR INDUK PANGKALPINANG

\section{ABSTRACT}

The market is the meeting place between the trader and the buyer so that the process of distributing products and services are often performed on the market both 
traditional and modern market. Distribution of products is usally done directly by distributors with vegetable trades so that there is a difference in price and volume on products sold by the vegetable traders. This study aims to count the volume of vegetables based on incoming types, as well as analyze the factors that influence the level of vegetables volume which come into Pasar Induk Pangkalpinang. This research was carried out from December 2017 up to January 2019 in Pasar Induk Pangkalpinang. The method used in this research was case study method. The sampling method was census method with 48 sample consist of 6 wholesalers, 2 distributors, and 40 retailers. The data analysis method used is qualitative descriptive and multiple linier regression analysis. The result shows The volume of vegetables supply in Pasar Induk Pangkalpinang based on the types, those are: $114.750 \mathrm{kgs}$ of leafy greenspermonth, $137.400 \mathrm{kgs}$ of fruits per month, $450 \mathrm{kgs}$ of flowery veggies per month, $17.400 \mathrm{kgs}$ of seed and nuts per month, and also $111.200 \mathrm{kgs}$ of tube rous roots per month. The factors influencing the level of vegetable supply volume, it is only 6 variables among 7 estimator variables that statistically influenceon 5\% level, which is sig $<0.05$, price $\left(X_{1}\right)$, profit $\left(X_{2}\right)$, transportation $\left(X_{4}\right)$, availibility of vegetable $\left(D_{1}\right)$, quality of vegetable $\left(D_{2}\right)$ and supplier area $\left(D_{3}\right)$.

Keywords: market, supply chain, vegetables and supply volume

\section{PENDAHULUAN}

Pasar merupakan tempat pertemuan antara pedagang dan pembeli sehingga proses pendistribusian produk dan jasa sering dilakukan di pasar baik pasar tradisional maupun pasar modern. Pasar tradisional merupakan pasar yang banyak tersebar di berbagai daerah, mulai dari daerah perkotaan hingga daerah pedesaan atau terpencil. Pasar tradisional biasanya masih bersifat tradisional serta penjual dan pembeli saling bertatap muka dan terjadi proses tawar menawar dalam transaksinya. Pasar tradisional berlokasi di tempat terbuka dan biasanya bangunan yang terdapat di pasar berupa toko dan kios. Pendistribusian produk biasanya dilakukan secara langsung oleh distributor dengan pedagang sayuran sehingga terdapat perbedaan harga dan volume pada produk yang di jual oleh pedagang sayuran tersebut.

Pasar tradisional merupakan salah satu pemasok komoditas pertanian, sehingga pasar tradisional biasanya digunakan pedagang sayuran yang merupakan penduduk untuk memasarkan produk pertaniannya, seperti buah-buahan, sayur-sayuran dan tanaman perkebunan.Namun, pasokan sayuran di pasar tidak hanya berasal dari pedagang sayuran itu sendiri melainkan terdapat pedagang besar atau tengkulak dan agen sayuran yang memasok pasokan sayuran yang berasal dari petani, pedagang antar wilayah serta kebun sendiri kemudian dijual ke pedagang pengecer. Sehingga kegiatan tersebut membentuk sebuah hubungan yang disebut rantai pasok atau supply chain.

Menurut Assauri (2011) dalam Kambey (2016), rantai pasok atau supply chain merupakan rangkaian hubungan antar perusahaan atau aktivitas yang melaksanakan penyaluran pasokan barang atau jasa dari tempat asal sampai ke tempat pembeli atau pelanggan. Ada lima komponen utama atau pelaku dalam supply chain, yaitu supplier (pemasok), 
manufacturer (pabrik pembuat barang), distributor (pedagang besar), retailer (pengecer) dan customer (pelanggan).

Provinsi Kepulauan Bangka Belitung memiliki 87 pasar tradisional dengan jumlah pedagang sebanyak 9.129 orang dengan tempat berjualan atau kios sebanyak 1927 kios dan lapak sebanyak 3483 lapak. Kota Pangkalpinang, memiliki 10 pasar tradisional dengan jumlah pedagang sebanyak 1751 orang, dan mempunyai kios dan lapak sebanyak 495 kios dan 980 los (Dinas Perindustrian dan
Perdagangan Provinsi Kepulauan Bangka Belitung, 2017).

Pangkalpinang merupakan ibukota dari Provinsi Kepulauan Bangka Belitung dengan karakteristik daerah kepulauan yang mempunyai iklim tropis serta curah hujan sehingga memiliki potensi dalam komoditas pertanian terutama sayuran hortikultura. Adapun luas tanam, luas panen, produksi dan produktivitas sayuran di Kota Pangkalpinang dapat dilihat di Tabel 1.

Tabel 1. Luas Tanam, Luas Panen, Produksi dan Produktivitas Tanaman Sayuran di Kota Pangkalpinang Tahun 2016

\begin{tabular}{llcccc}
\hline No & Komoditas & $\begin{array}{c}\text { Luas } \\
\text { Tanam } \\
(\mathrm{Ha})\end{array}$ & $\begin{array}{c}\text { Luas } \\
\text { Panen } \\
(\mathrm{Ha})\end{array}$ & $\begin{array}{c}\text { Produksi } \\
\text { (Ton) }\end{array}$ & $\begin{array}{c}\text { Produktivitas } \\
\text { (Ton/Ha/Th) }\end{array}$ \\
\hline 1. & Bayam & 7 & 6 & 30 & 5,00 \\
2. & Cabe Besar & 5 & 4 & 59 & 14,75 \\
3. & Cabe Rawit & 4 & 3 & 32 & 12,20 \\
4. & Kacang & 9 & 8 & 88 & 11,00 \\
& Panjang & & & 67 & 7,44 \\
5. Kangkung & 10 & 9 & 70 & 8,69 \\
6. & Ketimun & 9 & 8 & 18 & 9,00 \\
7. & Petsai/Sawi & 2 & 2 & 37 & 9,25 \\
8. Terung & 5 & 4 & 30 & 30,00 \\
9. & Tomat & 3 & 1 & & \\
\hline
\end{tabular}

Sumber: Dinas Pangan dan Pertanian Kota Pangkalpinang, 2017

Berdasarkan tabel 1, Kota Pangkalpinang memiliki beberapa lahan untuk menanam dan memproduksi beberapa komoditas sayuran, yaitu bayam, cabe besar, cabe rawit, kacang panjang, kangkung, ketimun, petsai/sawi, terung dan tomat. Namun, tidak semua jenis komoditas sayuran ditanam sehingga kebutuhan masyarakat terhadap sayuran dapat tidak terpenuhi karena kurangnya jumlah pasokan sayuran. Sehingga perlu diidentifikasi terhadap struktur pasar serta pola distribusi berikut perilaku produsen, pedagang besar, pedagang eceran dalam pasokan dan jalur distribusi komoditas sayuran di Pasar Induk Kota Pangkalpinang.

Pasar Induk merupakan pasar tradisional terbesar yang terdapat di Kota Pangkalpinang. UPT (Unit Pelaksana Teknis) Pasar Induk mempunyai cakupan beberapa pasar yang masuk ke dalam wilayahnya, yaitu: Pasar Seputaran Ramayana, Pasar Parit Lalang, Pasar Pagi, Pasar Rumput, Pasar Kranas, Pasar Kemangi 
dan Pasar Aneka Buah atau Pasar Burung. Pasar Induk mempunyai fasilitas seperti bangunan serta kios dan los yang digunakan para pedagang untuk menjual barang dagangan seperti bumbu-bumbu, sayur-sayuran, buah-buahan, ayam, daging, ikan serta sembako (UPT Pasar Induk Kota Pangkalpinang, 2017). Pedagang sayuran di Pasar Induk biasanya mengambil pasokan sayur melalui pedagang besar maupun kebun milik sendiri. Adapun sumber pasokan sayuran melalui pedagang besar berasal dari Kabupaten Bangka yaitu, Balunijuk, Pagarawan, Sungailiat, Koba, Kemuja, Mendo Barat, Labu, Dalil, Bakam, Kelapa dan Kabupaten Bangka Tengah yaitu Benteng. Dan sumber pasokan sayuran dari agen sayuran berasal dari Jakarta, Kendari, Padang, Yogyakarta, Bengkulu, Medan, Brebes, Palembang.

Cakupan Pasar Induk yang diambil sebagai tempat penelitian adalah Pasar Kranas dan Pasar Kemangi yang memiliki pedagang berjumlah 166 orang dengan jumlah pedagang sayuran sebanyak 48 orang, pedagang ayam dan daging sebanyak 54 orang, pedagang ikan sebanyak 26 orang, pedagang buah sebanyak 10 orang dan lain-lain sebanyak 28 orang (UPT Pasar Induk Kota Pangkalpinang, 2017). Sehingga, sangat menarik untuk meneliti dan menelusuri pola rantai pasokan di Pasar Induk Pangkalpinang dari kemungkinan kurangnya jumlah pasokan sayuran karena jumlah produksi komoditas sayuran di Kota Pangkalpinang yang terbatas serta terdapat 2 pasar didalamnya dan memiliki wilayah yang lebih luas dari pasar lainnya, sehingga menyebabkan pedagang sayuran memiliki lokasi yang berbeda berdasarkan lokasi pasar.

Distributor dan pedagang juga harus mengetahui jenis dan volume sayuran, karena jenis sayuran berbeda-berbeda sehingga perlakuan yang diberikan juga berbeda dalam pengangkutan maupun pendistribusiannya.Hal ini dikarenakan mengingat karakteristik sayuran yang mudah rusak maupun busuk bila tidak dilakukan penanganan yang tepat dalam pengangkutan maupun pendistribusiannya.Adapun juga faktor-faktor yang berpengaruh terhadap volume sayuran di Pasar Induk Kota Pangkalpinang juga belum diketahui.Sehingga berdasarkan latar belakang tersebut peneliti tertarik melakukan penelitian mengenai "Analisis Rantai Pasokan Sayuran di Pasar Induk Kota Pangkalpinang".

\section{METODE PENELITIAN}

Pemilihan lokasi penelitian dilakukan secara purposive (sengaja) di Desa Lubuk Lingkuk. Penelitian ini akan dilaksanakan pada bulan Desember 2017 sampai bulan Januari 2019. Metode yang digunakan adalah metode studi kasus. Data dalam penelitian ini meliputi data primer dan data sekunder. Data primer diperoleh melalui pengamatan dan wawancara secara langsung diperoleh dari 6 orang pedagang besar, 2 orang agen sayuran dan 40 orang pedagang pengecer melalui panduan kuesioner. Sedangkan data sekunder untuk memberikan gambaran dilapangan atau merupakan data pendukung informasi yang diterima. Informasi data sekunder diperoleh dari berbagai instansi antara lain Dinas Perindustrian dan Perdagangan 
Provinsi Kepulauan Bangka Belitung, Dinas Pangan dan Pertanian Provinsi Kepulauan Bangka Belitung, UPT Pasar Induk Kota Pangkalpinang serta literatur lainnya yang terkait dengan penelitian ini seperti: jurnal, skripsi, tesis serta data dari internet. Analisis data menggunakan deskriptif kualitatif untuk menghitung volume di
Pasar Induk Kota Pangkalpinang dan deskriptif kuantitatif dengan metode analisis regresi linier berganda untuk menganalisis faktor-faktor yang mempengaruhi volume pasokan sayuran di Pasar Induk Kota Pangkalpinang. Secara umum model regresi linier berganda untuk sampel, yaitu:

$$
Y=\beta_{0}+\beta_{1} X_{1}+\beta_{2} X_{2}+\beta_{3} X_{3}+\ldots .+\beta_{n} X_{n}+e
$$

Dimana:

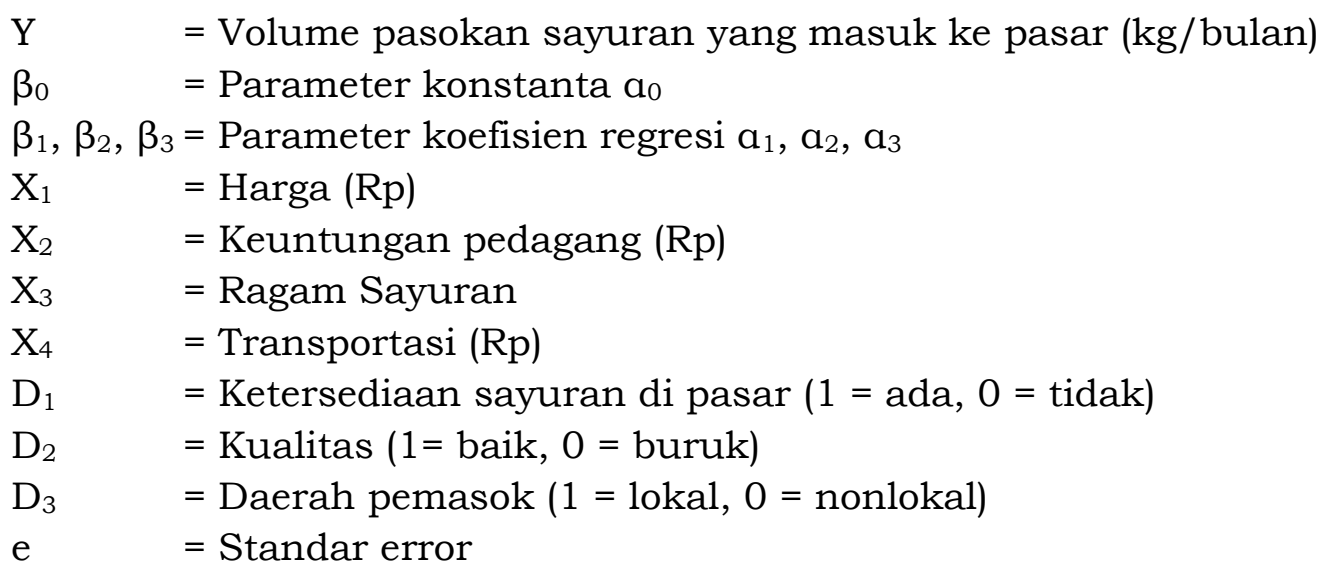

\section{HASIL DAN PEMBAHASAN}

\section{Volume Pasokan Sayuran Di Pasar Induk Kota Pangkalpinang}

Pedagang sayuran di Pasar Induk Kota Pangkalpinang tidak menyerap sayuran setiap hari, karena tidak setiap hari sayuran yang dijual akan habis dalam sehari. Pedagang akan membuat stok dari sayuran yang tidak habis untuk dijual kembali keesokan harinya. Pasokan sayuran yang disimpan disesuaikan dengan karakteristik dari sayuran tersebut, karena terdapat beberapa sayuran yang mudah rusak dan busuk bila disimpan dalam waktu yang lama seperti sayuran daun yang waktu penyimpanannya relatif singkat sekitar dua hari. Sedangkan sayuran dapat disimpan dalam waktu lama adalah jenis sayuran umbi-umbian. Jenis sayuran umbi dapat disimpan dalam waktu yang cukup lama sekitar tujuh hari karena tidak mudah rusak dan busuk tergantung dari cara penyimpanan pedagang sayuran. Pedagang sayuran telah memprediksikan pembelian sayuran yang akan dijual berdasarkan kondisi pasar.

Volume pasokan sayuran di Pasar Induk Kota Pangkalpinang adalah 381.200 kilogram per bulan. Namun, volume tersebut masih dapat bertambah tergantung dengan ketersediaan sayuran di daerah pemasok. Pada waktu penelitian ketersediaan sayuran terbatas karena terkendala dengan cuaca yang tidak terduga menyebabkan sayuran yang berasal dari petani terbatas. Hal tersebut akan mempengaruhi ketersediaan dan harga dari sayuran tersebut. Adapun volume pasokan sayuran berdasarkan jenisnya di 
Pasar Induk Kota Pangkalpinang tersaji pada Tabel 2.

Tabel 2. Volume Pasokan Sayuran Berdasarkan Jenis Sayuran di Pasar Induk Kota Pangkalpinang Tahun 2018

\begin{tabular}{lcc}
\hline Jenis Sayuran & Volume Pasokan (kg/bulan) & Persentase (\%) \\
\hline Daun & 114.750 & 30,10 \\
Buah & 137.400 & 36,04 \\
Bunga & 450 & 0,12 \\
Biji dan Polong & 17.400 & 4,56 \\
Umbi & 111.200 & 29,17 \\
\hline Total & 381.200 & 100,00 \\
\hline
\end{tabular}

Sumber: Olahan Data Primer, 2018

Berdasarkan Tabel 2, volume pasokan sayuran jenis buah merupakan jenis sayuran yang memiliki pasokan sayuran terbanyak di Pasar Induk Kota Pangkalpinang sebesar 137.400 kilogram per bulan dengan persentase 36,04 persen. Ini dikarenakan jenis sayuran buah seperti cabai merah, cabai rawit dan cabai hijau memberikan kontribusi yang besar karena merupakan bumbu dasar yang diperlukan setiap hari untuk kebutuhan rumah tangga sehingga permintaan akan jenis sayuran buah tersebut banyak.

Jenis sayuran yang juga memiliki permintaan yang banyak adalah jenis sayuran daun dan umbi. Walaupun tidak sebanyak jenis sayuran buah, jenis sayuran daun dan umbi juga memiliki volume pasokan yang banyak yaitu 114.750 kilogram per bulan dan 111.200 kilogram per bulan dengan persentase 30,10 persen dan 29,17 persen. Ini juga dikarenakan rata-rata jenis sayuran daun memiliki banyak permintaan dari konsumen yang mengkonsumsi sendiri dan untuk konsumen yang memiliki usaha kuliner. Jenis sayuran daun seperti sawi, kangkung, bayam, daun bawang, daun seledri, kol dan selada. Sedangkan rata-rata jenis sayuran umbi ini juga merupakan sebagai bumbu masakan sehingga setiap hari memiliki permintaan yang banyak. Jenis sayuran umbi sebagai bumbu seperti bawang merah, bawang putih, bawang bombay, kencur, laos, kunyit dan jahe. Sedang sayuran seperti kentang dan wortel juga memberikan volume pasokan yang besar untuk jenis sayuran umbi dikarenakan kuantitasnya relatif berat.

Sementara jenis sayuran yang memiliki volume pasokan terendah adalah jenis sayuran bunga sebesar 450 kilogram per bulan dengan persentase 0,12 persen. Ini dikarenakan agen sayuran tidak memasok sayuran dengan jenis bunga seperti kembang kol dan brokoli karena harganya mahal dan mudah busuk. Jenis sayuran ini hanya dijual oleh satu orang pedagang pengecer karena mengambil sayuran tersebut dari daerah asal pedagang. Berdasarkan jenis sayurannya, volume pasokan sayuran terbanyak dimiliki oleh jenis sayuran buah dan volume pasokan sayuran terendah dimiliki oleh jenis sayuran bunga. 
Berbeda dengan penelitian Fitri (2017) di Pasar Baru Muntok dengan hasil volume sayuran yang masuk ke Pasar Baru Muntok berdasarkan jenisnya adalah: jenis sayuran daun $58.820 \mathrm{~kg}$ per bulan, jenis sayuran buah $61.215,5 \mathrm{~kg}$ per bulan, jenis sayuran bunga $990 \mathrm{~kg}$ per bulan, jenis sayuran biji dan polong $10.465 \mathrm{~kg}$ per bulan dan jenis sayuran umbi 78.550 kg per bulan.

\section{Faktor-Faktor yang Mempengaruhi Volume Pasokan Sayuran di Pasar Induk Kota Pangkalpinang}

Untuk mengetahui faktor-faktor yang mempengaruhi volume pasokan sayuran di Pasar Induk Kota Pangkalpinang, penulis menggunakan metode Analisis Regresi Linier Berganda dengan menggunakan program Statistical Product and Service Solution (SPSS) versi 24. Analisis Regresi Linier Berganda digunakan untuk menganalisis variabel yang signifikan yang mempengaruhi volume pasokan sayuran di Pasar Induk Kota Pangkalpinang. Dalam melakukan analisis regresi linier berganda dilakukan uji asumsi klasik dan uji statistika, untuk lebih jelasnya akan dibahas dibawah ini.

1. Uji Asumsi Klasik

Uji asumsi klasik terdiri dari uji normalitas, uji multikolinearitas, uji heterokedastisitas dan uji autokorelasi.

a. Uji Normalitas

Berdasarkan hasil uji normalitas pada Normal Probability

Tabel 3. Model Summary

\begin{tabular}{|c|c|c|c|c|c|}
\hline $\begin{array}{l}\text { Mo } \\
\text { del }\end{array}$ & $\mathrm{R}$ & $\begin{array}{c}\mathrm{R} \\
\text { Squ } \\
\text { are }\end{array}$ & $\begin{array}{c}\text { Adjus } \\
\text { ted R } \\
\text { Squa } \\
\text { re }\end{array}$ & $\begin{array}{l}\text { Std. } \\
\text { Error } \\
\text { of the } \\
\text { Estim }\end{array}$ & $\begin{array}{l}\text { Durb } \\
\text { in- } \\
\text { Wats } \\
\text { on }\end{array}$ \\
\hline
\end{tabular}

Plots dapat dilihat pada lampiran 8, titik-titik menyebar di sekitar garis diagonal dan mengikuti arah garis diagonal dan pada uji one-sample Kolmogorov-Smirnov test, nilai signifikansi lebih besar dari 0,05 yaitu 0,200 sehingga model regresi yang digunakan dalam penelitian ini terdistribusi secara normal.

b. Uji Multikolinearitas Berdasarkan hasil uji multikolinearitas pada lampiran 8, nilai tolerance semua variabel independent bernilai lebih dari 0,1 sedangkan nilai VIF tidak semua variabel independent bernilai kurang dari 10 yaitu variabel harga modal dan keuntungan pedagang. $\mathrm{Hal}$ ini dikarenakan terdapat angka pada data yang diambil terlalu besar dan terlalu kecil pada kedua variabel sehingga angka tersebut lebih menonjol dibandingkan dengan angka lainnya yang lebih seragam.

c. Uji Heteroskedastisitas

Berdasarkan hasil uji heteroskedastisitas grafik Scatterplot padalampiran 8, menunjukkan plot antara residual dengan predicted value, titik-titiknya menyebar diatas dan dibawah angka 0 pada sumbu $\mathrm{Y}$, juga tidak membentuk suatu pola tertentu maka dapat disimpulkan bahwa variabel bebas yang digunakan tidak terjadi heteroskedastisitas.

d. Uji Autokorelasi

Adapun hasil uji autokorelasi dapat dilihat pada Tabel 29, dibawah ini.

\begin{tabular}{cccccc}
\hline 1 &, 99 &, 985 &, 982 &, 1392 & 1,79 \\
& $2^{\text {a }}$ & & & 2 & 0 \\
\hline \multicolumn{4}{c}{ Sumber: } \\
2018 & Olahan & Data & Primer, \\
& & & &
\end{tabular}

https://doi.org/10.24843/SOCA.2019.v13.i01.p09 
Berdasarkan Tabel 3, dapat dilihat nilai Durbin Watson (DW) yairu 1,790. Dari hasil tersebut, dapat dilihat bahwa nilai DW diantara -2 sampai +2 yang berarti tidak ada korelasi, sehingga dapat disimpulkan bahwa dalam model regresi tidak terjadi autokorelasi.

\section{Uji Statistika}

a. Koefisien Determinasi $\left(\mathrm{R}^{2}\right)$

Uji koefisien determinasi $\left(R^{2}\right)$ bertujuan untuk mengukur tingkat korelasi atau pengaruh antara variabel independent secara bersama-sama (simultan) terhadap variabel dependent. Berdasarkan hasil analisis regresi linier berganda didapat hasil koefisien determinasi ( $\left.\mathrm{R}^{2}\right)$ sebesar 0,985 dan hasil Adjusted $R$ Square sebesar 0,982. Berdasarkan Tabel 28, dapat dilihat bahwa nilai Adjusted $R$
Square sebesar 0,982 atau 98,2 persen. Hal ini berarti bahwa sebanyak 98,2 persen variabel harga sayuran, keuntungan pedagang, jumlah ragam sayuran, transportasi, ketersediaan sayuran, kualitas sayuran dan daerah pemasok mempengaruhi variabel terikat volume pasokan sayuran. Sedangkan sisanya sebesar 1,8 persen dipengaruhi oleh variabel lain yang tidak dimasukkan kedalam model regresi linier berganda.

b. Uji Signifikansi Simultan (Uji F) Uji simultan atau uji $F$ bertujuan untuk apakah semua variabel independent atau bebas yang dimasukkan dalam model mempunyai pengaruh secara bersama-sama terhadap variabel dependent atau terikat. Adapun nilai uji $\mathrm{F}$ dapat dilihat pada Tabel 4.

Tabel 4. Model Persamaan ANOVA

\begin{tabular}{llccccc}
\hline \multicolumn{1}{c}{ Model } & $\begin{array}{c}\text { Sum of } \\
\text { Squares }\end{array}$ & Df & $\begin{array}{c}\text { Mean } \\
\text { Square }\end{array}$ & F & Sig. \\
\hline 1 & Regression & 51,097 & 7 & 7,300 & 376,638 &, $000^{\mathrm{b}}$ \\
& Residual &, 775 & 40 &, 019 & & \\
& Total & 51,872 & 47 & & & \\
\hline
\end{tabular}

Sumber: Olahan Data Primer, 2018

Berdasarkan Tabel 4, menunjukkan nilai signifikansi sebesar 0,000 atau 0 persen maka dapat disimpulkan bahwa secara bersama-sama variabel independen (X) atau variabel bebas (harga sayuran, keuntungan pedagang, jumlah ragam sayuran, transportasi, ketersediaan sayuran, kualitas dan daerah pemasok) berpengaruh terhadap variabel volume pasokan sayuran $(\mathrm{Y})$. Sehingga dapat disimpulkan p-value (sig) < 0.05, maka $\mathrm{H}_{0}$ ditolak dan $\mathrm{H}_{1}$ diterima, artinya variabel bebas secara bersama-sama mempengaruhi variabel terikat.

c. Uji Signifikansi Parameter Individual (Uji t)

Uji t bertujuan untuk menguji pengaruh signifikan variabel independen terhadap variabel dependen secara individual. Adapun hasil uji t dapat dilihat pada Tabel 5 . 
Tabel 5. Uji Signifikansi Parameter Individual

\begin{tabular}{llcccc}
\hline \multirow{2}{*}{ Model } & \multicolumn{2}{c}{$\begin{array}{c}\text { Unstandardized } \\
\text { Coefficients }\end{array}$} & \multirow{2}{*}{ T } & Sig. \\
\cline { 3 - 4 } & & B & Std. Error & & \\
\hline 1 & (Constant) & $-8,306$ &, 421 & $-19,725$ &, $000^{*}$ \\
& Ln_Harga_Modal &, 228 &, 089 & 2,561 &, $014^{*}$ \\
& Ln_Keuntungan &, 512 &, 091 & 5,605 &, $000^{*}$ \\
& Ln_Ragam_Sayuran &, 055 &, 074 &, 739 &, 464 \\
& Ln_Transportasi &, 303 &, 056 & 5,431 &, $000^{*}$ \\
Kualitas_Sayuran &,- 115 &, 056 & $-2,039$ &, $048^{*}$ \\
& Ketersediaan_Sayuran &,- 153 &, 055 & $-2,772$ &, $008^{*}$ \\
& Daerah_Pemasok &, 152 &, 057 & 2,651 &, $011^{*}$ \\
\hline
\end{tabular}

Ket: * : variabel yang berpengaruh

Sumber: Olahan Data Primer, 2018

Berdasarkan Tabel 5, dapat dilihat dari ke tujuh variabel bebas terdapat enam variabel bebas yang berpengaruh terhadap variabel volume pasokan sayuran di Pasar Induk Kota Pangkalpinang yaitu variabel harga modal, keuntungan pedagang, transportasi, kualitas sayuran, ketersediaan sayuran dan daerah pemasok. Nilai signifikansi variabel harga modal yaitu 0,014, nilai signifikansi variabel keuntungan pedagang yaitu 0,000 , nilai signifikansi variabel transportasi yaitu 0,000, nilai signifikansi variabel kualitas sayuran yaitu 0,048 , nilai signifikansi variabel ketersediaan sayuran yaitu 0,008 dan nilai signifikansi variabel daerah pemasok yaitu 0,011. Dimana kaidah pengambilan keputusan yaitu apabila nilai $p$-value (sig) $<0.05$, maka $\mathrm{H}_{0}$ ditolak dan $\mathrm{H}_{1}$ diterima, artinya variabel bebas secara individu mempengaruhi variabel terikat. Jadi, dapat disimpulkan variabel bebas dalam penelitian ini berpengaruh nyata terhadap variabel terikat atau volume pasokan sayuran.

Maka setelah dilakukan pengujian, hasil akhir nilai koefisien persamaan dan estimasi faktor-faktor yang mempengaruhi volume pasokan sayuran di Pasar Induk Kota Pangkalpinang sebagai berikut: $\mathrm{Y}=-8,306+0,228 \mathrm{X}_{1}+0,512 \mathrm{X}_{2}+$ $0,303 \mathrm{X}_{4}-0,153 \mathrm{D}_{1}-0,115 \mathrm{D}_{2}+0,152$ $\mathrm{D}_{3}$

Adapun interpretasi dari masing-masing variabel yang berpengaruh terhadap volume pasokan sayuran di Pasar Induk Kota Pangkalpinang sebagai berikut:

\section{Harga $\left(\mathrm{X}_{1}\right)$}

Berdasarkan hasil analisis regresi linier berganda pada Tabel 5 menunjukkan nilai signifikansi sebesar 0,014 lebih kecil dari 0,05 sesuai dengan kriteria pengujian pada penelitian ini menyatakan bahwa $\mathrm{H}_{0}$ ditolak bila $p$-value $(\mathrm{sig})<0.05$ yang artinya variabel harga sayuran secara parsial berpengaruh signifikan terhadap variabel volume pasokan sayuran di Pasar Induk Kota Pangkalpinang.Selanjutnya nilai koefisien sebesar 0,228, yang artinya hubungan variabel harga sayuran dengan volume pasokan sayuran bersifat positif. Sehingga, jika harga sayuran meningkat sebesar satu 
rupiah maka volume pasokan sayuran bertambah sebesar 0,228 kilogram. Harga sayuran yang dimaksud adalah modal yang dikeluarkan pedagang sayuran. Jika harga sayuran tinggi maka modal yang dikeluarkan pedagang semakin besar dan volume pasokan sayuran juga akan berkurang dan juga sebaliknya. Hal ini sesuai dengan penelitian Sudrajat (2014), yang membuktikan adanya hubungan langsung antara harga dengan volume pasokan. Harga modal dagang berpengaruh karena sangat dibutuhkan dalam menjalankan usaha sayuran dengan tingkat fluktuatif harga yang tinggi yang dipengaruhi oleh musim panen.Andris (2014) menyatakan harga sayuran mempengaruhi volume sayuran, karena harga dari setiap sayuran dan ragam sayuran yang diperoleh setiap pedagang berbeda sehingga biaya yang dikeluarkan oleh pedagang juga berbeda-beda. Selain itu harga dari daerah pemasok sayuran juga mempengaruhi harga yang dikeluarkan pedagang karena tidak semua pedagang memperoleh sayuran dari daerah pemasok yang sama.

\section{Keuntungan Pedagang $\left(\mathrm{X}_{2}\right)$}

Berdasarkan hasil analisis regresi linier berganda pada Tabel 5, menunjukkan nilai signifikansi sebesar 0,000 lebih kecil dari 0,05 sesuai dengan kriteria pengujian pada penelitian ini menyatakan bahwa $\mathrm{H}_{0}$ ditolak bila $p$-value (sig) < 0.05 yang artinya variabel keuntungan secara parsial berpengaruh signifikan terhadap variabel volume pasokan sayuran di Pasar Induk Kota Pangkalpinang. Nilai koefisien sebesar 0,512 , yang artinya variabel keuntungan dengan variabel volume pasokan sayuran bersifat positif.
Sehingga, jika keuntungan meningkat sebesar satu rupiah maka volume pasokan sayuran bertambah sebesar 0,512 kilogram. Artinya jika semakin tinggi keuntungan maka volume pasokan sayuran semakin banyak. Hal ini sesuai dengan hasil wawancara dimana keuntungan yang diperoleh akan digunakan kembali sebagai modal untuk membeli sayuran kembali. Hal ini seseuai dengan penelitian Hadiguna (2007) dan Fitri (2017) yang menyatakan bahwa keuntungan berpengaruh positif terhadap volume pasokan, semakin tinggi keuntungan maka volume pasokan semakin banyak.

\section{Transportasi $\left(\mathrm{X}_{4}\right)$}

Berdasarkan hasil analisis regresi linier berganda pada Tabel 5 , menunjukkan nilai signifikansi sebesar 0,000 lebih kecil dari 0,05 yang artinya variabel transportasi secara parsial berpengaruh signifikan terhadap variabel volume pasokan sayuran di Pasar Induk Kota Pangkalpinang. Nilai koefisien sebesar 0,303, yang artinya variabel keuntungan dengan variabel volume pasokan sayuran bersifat positif. Sehingga, jika biaya transportasi meningkat sebesar satu rupiah maka volume pasokan sayuran bertambah sebesar 0,303 kilogram. Transportasi dilihat dari segi pembelian bahan bakar oleh pedagang sayuran yaitu pedagang besar dan agen sayuran. Transportasi sangat mempengaruhi volume pasokan karena bila terjadi hambatan atau kendala pada transportasi akan mempengaruhi volume pasokan di Pasar Induk Kota Pangkalpinang. Hal ini sesuai dengan penelitian Tumbel (2016), yang menyatakan transportasi mempengaruhi volume pasokan 
karena dalam proses pengangkutan barang, biaya operasi bukanlah satusatunya faktor yang perlu dipertimbangkan, namun hal-hal seperti kapasitas kendaraan dan kerusakan jalan dapat menghambat proses distribusi pasokan sayuran.

4. Ketersediaan Sayuran $\left(D_{1}\right)$ Berdasarkan hasil analisis regresi linier berganda pada Tabel 5, menunjukkan nilai signifikansi sebesar 0,008 lebih kecil dari 0,05 sesuai dengan kriteria pengujian pada penelitian ini menyatakan bahwa $\mathrm{H}_{0}$ ditolak bila $p$-value (sig) < 0.05 yang artinya variabel ketersediaan sayuran secara parsial berpengaruh signifikan terhadap variabel volume pasokan sayuran di Pasar Induk Kota Pangkalpinang. Nilai koefisien sebesar 0,153 , yang artinya variabel keuntungan dengan variabel volume pasokan sayuran bersifat negatif. Sehingga, apabila sayuran tersedia maka pasokan sayuran dipasar lebih rendah atau berkurang 0,153 kilogram dibandingkan dengan sayuran tidak tersedia. Ketersediaan sayuran sangat mempengaruhi volume pasokan, jika ketersediaan volume sayuran banyak maka harga sayuran akan turun sedangkan jika ketersediaan volume sayuran sedikit maka harga sayuran tersebut akan naik. Hal ini sesuai dengan penelitian Kharisma (2014), yang menyatakan bahwa ketersediaan sayuran berpengaruh nyata terhadap volume pasokan, hal ini dikarenakan pedagang sayuran selalu memperhatikan volume sayuran yang diperdagangkan serta dapat memprediksi pembelian selanjutnya, secara tidak langsung pedagang tersebut membatasi volume pasokan. Semakin banyak sayuran yang tersedia maka volume pasokan dikurangi, karena disesuaikan dengan permintaan konsumen mengingat karakteristik sayuran yang mudah rusak.

\section{Kualitas Sayuran $\left(\mathrm{D}_{2}\right)$}

Berdasarkan hasil analisis regresi linier berganda pada Tabel 5, menunjukkan nilai signifikansi sebesar 0,048 lebih kecil dari 0,05 sesuai dengan kriteria pengujian pada penelitian ini menyatakan bahwa $\mathrm{H}_{0}$ ditolak bila $p$-value(sig) $<0.05$ yang artinya variabel keuntungan secara parsial berpengaruh signifikan terhadap variabel volume pasokan sayuran di Pasar Induk Kota Pangkalpinang. Nilai koefisien sebesar 0,115 , yang artinya variabel kualitas sayuran dengan variabel volume pasokan sayuran bersifat negatif. Sehingga, apabila kualitas sayuran baik, maka pasokan sayuran dipasar lebih rendah atau berkurang dari 0,115 kilogram dibandingkan dengan kualitas sayuran yang buruk. Hal ini sesuai dengan penelitian Asmidah (2013), yang menyatakan bahwa kualitas sayuran yang disediakan untuk diperdagangkan ada yang baik dan ada yang buruk. Sayuran yang berkualitas buruk kebanyakan tersedia pada agen sayuran dan pedagang besar, hal ini dikarenakan sayuran tersebut diperoleh oleh dari pemasok dimana pedagang besar tersebut tidak dapat memilih sendiri kualitas daripada sayuran tersebut.

6. Daerah Pemasok sayuran $\left(D_{3}\right)$ Berdasarkan hasil analisis regresi linier berganda pada Tabel 5, menunjukkan nilai signifikansi sebesar 0,011 lebih kecil dari 0,05 sesuai dengan kriteria pengujian pada penelitian ini menyatakan bahwa $\mathrm{H}_{0}$ ditolak bila $p$-value (sig) $<0.05$ yang 
artinya variabel daerah pemasok secara parsial berpengaruh signifikan terhadap variabel volume pasokan sayuran di Pasar Induk Kota Pangkalpinang. Nilai koefisien sebesar 0,152 , yang artinya variabel daerah pemasok sayuran lokal dengan variabel volume pasokan sayuran bersifat positif. Sehingga, jika daerah pemasok sayuran lokalbertambah satu daerah maka volume pasokan sayuran bertambah sebesar 0,152 kilogram. Daerah pemasok sayuran mempengaruhi volume pasokan sayuran baik daerah pemasok lokal maupun non lokal. Pedagang sayuran yang mengambil sayuran dari daerah pemasok lokal berjumlah 27 orang sedangkan dari daerah non lokal berjumlah 21 orang. Oleh karena itu, jika daerah pemasok sayuran bertmbah maka volume pasokan sayuran juga akan bertambah. Hal ini sesuai dengan penelitian Sasmita (2012), yang menyatakan bahwa tambahan daerah pemasok berpengaruh terhadap volume pasokan. Daerah pemasok sayuran berpengaruh terhadap volume pasokan, karena semakin banyak sayuran yang berasal dari daerah pemasok lokal maka semakin banyak pula volume pasokan yang tersedia.

\section{KESIMPULAN}

Berdasarkan hasil penelitian yang telah dilakukan, diperoleh beberapa kesimpulan sebagai berikut:

1. Volume pasokan sayuran yang masuk ke Pasar Induk Kota Pangkalpinang berdasarkan jenisnya yaitu; jenis sayuran daun 114.750 kilogram per bulan, jenis sayuran buah 137.400 kilogram per bulan, jenis sayuran bunga 450 kilogram per bulan, jenis sayuran biji dan polong 17.400 kilogram perbulan dan jenis sayuran umbi 111.200 kilogram per bulan.

2. Faktor-faktor yang mempengaruhi tingkat volume pasokan sayuran diantara 7 variabel penduga terdapat6 variabel yang berpengaruh secara statistik pada taraf 5 persen, dimana sig < 0,05 yaitu harga sayuran $\left(\mathrm{X}_{1}\right)$ dengan signifikansi 0,043, keuntungan pedagang $\left(\mathrm{X}_{2}\right)$ dengan signifikansi 0,000, transportasi $\left(\mathrm{X}_{4}\right)$ dengan signifikansi 0,000, kualitas sayuran $\left(D_{1}\right)$ dengan signifikansi 0,048, ketersediaan sayuran $\left(\mathrm{D}_{2}\right) \quad$ dengan signifikansi 0,008 dan daerah pemasok $\left(\mathrm{D}_{3}\right)$ dengan signifikansi 0,011.

\section{DAFTAR PUSTAKA}

Andris, O. 2014.Faktor-Faktor yang Mempengaruhi Impor Sayuran di Kabupaten Kaimana Provinsi Papua Barat.Jurnal AGRIC. Fakultas Pertanian Uiversitas Gadjah Mada. Vol. 26, No. 1\&2, Juli-Desember 2014.

Asmidah. 2013. Faktor-Faktor yang Mempengaruhi Permintaan dan Penawaran Jeruk Manis di Pasar Tradisional Kota Medan Provinsi Sumatera Utara. Skripsi S1. Jurusan Agribisnis. Fakultas Pertanian. Universitas Sumatera Utara. Medan.

Dinas Perindustrian dan Perdagangan Provinsi Kepulauan Bangka Belitung. 2017. Data Pasar, Pedagang, Kios dan Lapak 
Tahun 2016.Provinsi Kepulauan Bangka Belitung.

Dinas Pangan dan Pertanian Provinsi Kepulauan Bangka Belitung. 2017. Luas Tanam, Luas Panen, Produksi dan Produktivitas Tanaman Sayuran dan Buah Semusim di Kota Pangkalpinang Tahun 2016. Provinsi Kepulauan Bangka Belitung.

Fitri, E.L. 2017.Analisis Rantai Pasokan Sayuran di Pasar Baru Kecamatan Muntok Kabupaten Bangka Barat. Skripsi S1. Jurusan Agribisnis. Fakultas Pertanian Perikanan dan Biologi.Universitas Bangka Belitung.Bangka.

Hadiguna., Rika, A. 2007. Alokasi Pasokan Berdasarkan Produk Unggulan Untuk Rantai Pasokan Sayuran Segar. Jurnal Teknik Industri.Fakultas Teknik Universitas Andalas Padang.Vol. 9, No. 2, Desember 2007.

Kharisma, E. 2014.Rantai Pasar Komoditas Pertanian dan
Dampaknya Terhadap Kegiatan Perdagangan Komoditas Pertanian Pasar Projo.Jurnal Wilayah dan Lingkungan, PT Nutrifood Balikpapan Indonesia. Vol. 2, No.1, April 2014.

Sasmita, S. 2012. Kajian Arus Barang di Pasar Induk Buah dan Sayur Cawangan Kota Yogyakarta. Skripsi S1. Pendidikan Geografi.Fakultas Ilmu Sosial.Universitas Negeri Yogyakarta.

Tumbel, E. 2016.Pemilihan Jalur Trasnportasi Komoditi Tomat Pada Pedagang di Pasar Tradisional Karombasan Manado.Jurnal Berkala Ilmiah Efisiensi. Universitas Sam Ratulangi, Manado. Vol. 16, No. 01 Tahun 2016.

Unit Pelaksana Teknis Pasar Induk Kota Pangkalpinang.2017. Profil Pasar dan Pedagang Pasar Induk Kota Pangkalpinang.Kota Pangkalpinang. 